\title{
Exploring the Self-Perceived Needs for Family Members Having Adult Critically Ill Loved Person: Descriptive Study
}

\author{
Suhair H. Al Ghabeesh1, Hana Abu-Snieneh², Luay Abu-Shahror1', Firas Abu-Sneineh ${ }^{3}$, \\ Mohammad Alhawamdeh ${ }^{4}$ \\ ${ }^{1}$ Faculty of Nursing, Al-Zaytoonah University, Amman, Jordan \\ ${ }^{2}$ Faculty of Nursing, University of Jordan, Amman, Jordan \\ ${ }^{3}$ College of Nursing, University of Dammam, Dammam, KSA \\ ${ }^{4}$ Critical Care Department, Prince Mohammed Bin Abdul Aziz Hospital, Alryad, KSA \\ Email: suhair alghabeesh@yahoo.com
}

Received 26 September 2014; revised 15 November 2014; accepted 2 December 2014

Copyright (C) 2014 by authors and Scientific Research Publishing Inc.

This work is licensed under the Creative Commons Attribution International License (CC BY). http://creativecommons.org/licenses/by/4.0/

(c) (i) Open Access

\section{Abstract}

The aim of this study was to explore the self-perceived needs for adult family members having critically ill patient, measure to how extent the needs are met and identify who meet the needs. The study took place in critical care units of the largest governmental hospital in Jordan. The study adopted a descriptive cross-sectional design. The Arabic translation of Critical Care Family Need Inventory was used to investigate the needs of convenient samples of 60 adult family members having critically ill patients. Findings revealed that 16 out of 45 need items on the CCFNI were rated as very important in $\mathbf{8 0} \%$ of the sample. The participants ranked need for assurance, information and proximity as the highest; need for support and comfort as the lowest. Families in this study viewed nurses as the most important source to meet their needs. A holistic approach of nursing management requires that nurses assess family needs using valid and reliable tools and develop intervention strategies to meet the identified needs.

\section{Keywords}

Family Needs, Critical Care Family Need Inventory (CCFNI), Critical Ill Patients

\section{Introduction}

The family is one of the basic units of society and it has a profound influence on its members. The simple defi- 
nition of family is that it is a unit made up of father, mother and their children. When a family member becomes ill, the repercussions for the family are notable; the illness affects the well-being of other family members, causing changes in the life of the whole family.

Having a loved critically ill patient in the intensive care unit may place considerable stress on families. The critical illness of a family member represents a potential crisis situation. Stress evolving from such situation usually makes family members feel disorganized and helpless; as a result, they often show difficulty in mobilizing appropriate coping resources [1]. The needs of families during this period are influenced by a variety of factors which are unique and individualize. Critical illness often occurs without warning and there is little time for patients and their families to prepare [2] [3]. Because ICU nurses are in continuous and close interaction with patients and family members, they are in an ideal position to help family members to cope with patient's critical illness in an adaptive way [3]. If family members' immediate needs can be met, desirable consequences both for family members and patients can be achieved; in order to meet family member's needs, ICU nurses must be able to identify their needs accurately [4]. As a health care professional working in an intensive care setting and caring for many critically ill patients, we believe that accurate identification and prioritization of family needs are very important in development of effective nursing interventions to help families to cope during the hospitalization of the critically ill patients. In Jordanian culture, provision of support and maintenance of strong bonds among people are highly encouraged, and visiting the sick, providing emotional and tangible support to others represent a favorable act. The aim of this study was to explore the self-perceived needs for adult family members having critically ill patient, measure the degree of important needs, find out the priority needs in the "very important" need category, measure to what extent the needs are met, identify who meet the needs, and analyze the relationship between adult family members' needs and their demographic characteristics. Family may be viewed as having both structure components and function components. A family is then defined as a set of interacting individuals who are usually related by blood, marriage or adoption and are interdependent in caring out relevant functions through their respective roles [5]. Family member is the individual who visited the patient in ICU regardless of his/her relationship to the patient [6]. Regarding Jordanian families, any change among family members can disturb relationships and create anxiety and stress in other members. A common saying for the prophet Mohammad is that "a Moslem to another Moslem is like one body; if an organ complains, the other organs respond with insomnia and fever" [7]. In other words, provision of support and maintenance of strong bond among people are highly encouraged in Arabic-Islamic culture. There is a strong desire for every Jordanian individual to maintain their relationships, obligations and roles. Family members are not only biologically related, but also socially and emotionally involved in every aspect of life. It is now widely recognized that hospitalization of a family member in a critical care unit results in a number of psychological and emotional problems, not only for the patient, but also for his/her family [8]. The family may play an important function in the course of an intensive care patient's illness; they are important to be considered in patient care [9]. A major study which identified a number of perceived needs of relatives of critically ill patient was undertaken by Molter [2]. The study found that needs addressing hope, information and visit were rated as the highest, while the need helping in providing care for the patient was rated as the lowest. Leske [3] replicated Molter work in ICU; she added open-ended question to identify needs, naming the resulting instrument—-the Critical Care Family Need Inventory (CCFNI).

There was literature supporting the need for information among family members [10]. Family members of medical patient rated information need significantly more important than of surgical patient [11]. Female family members were more anxious and persistent in obtaining updated information about the patient and ensuring that the best care was given [8]. This comes into line with the finding of another study which showed that female relatives generally report higher need levels than male relatives and family needs appear to increase with the relatives age [12]. Family representatives perceived that their physicians are more controlled than nurses, and their nurses are friendlier and less hostile than physicians [13].

\section{Research Question}

What are the needs of family members in Arabic-Islamic culture of critically ill patient in the ICU, now? What are the most important needs to the relatives? Are these needs being met, if so, by whom? Are the needs of family members affected by gender, age, experience of visiting ICU and characteristic of patient? 


\section{Methodology}

\subsection{Design and Sample}

Descriptive cross-sectional design was used in this study. The study was conducted in critical care units in the largest governmental hospital in Jordan. These units contained 50 beds that receive patients with variety of critical, life-threatening illnesses, and trauma patients. Convenient sample was selected from family members who come to visit their critically ill patients. The family members who met the inclusion criteria were interviewed after the participant voluntary agreed to participate in this study and signed the informed consent. The inclusion criteria were Jordanian, ability to speak and understand Arabic language, willing to complete the questionnaires within 18 - 72 hours of the patient's admission to ICU, age of participant 18 years or older who considered themselves as having the most intimate relationship with the patient. The exclusion criteria were family member in confused state and can’t express their feeling, always crying.

\subsection{Procedure}

Ethical approval to conduct the study was obtained from the IRB at Ministry of Health and from hospital directors. Once a participant was identified, the researcher provided adequate information about the significance and purposes of the study. Participants were assured that participation is voluntary. In addition, they were told to feel free to withdraw at any time and that their responses will be treated confidentially, anonymity, and no harm. Furthermore, they informed that if any psychological changes happened the interview will stop and the family member will assured and suitable management will done. Additionally, administer questionnaire through interviews. Interviews are considered superior to self-administered questionnaire for most research purposes because of too many reasons such as interviews offer some protection against ambiguous or confusing questions, respondents are less likely to give do not know responses, or to leave a question unanswered in an interview than on questionnaire, and many people simply cannot fill out questionnaire including illiterate, elderly, or uneducated individuals [14]. The permission to use CCFNI tool from Leske was obtained.

\subsection{Instrument}

The Critical Care Family Needs Inventory \{CCFNI\} consists of 45-items. Family members responded to the need statements by rating each one on a four-point Likert-type scale in the following format: 1 -not important, 2-slightly important, 3-important, 4-very important. Family members were asked to state whether these needs had been met and, if so, by whom.

The questionnaire was translated to the Arabic language and back translated by the researchers and linguistic oriented person. The final Arabic version was tested to assess the feasibility of the study, provide data about recruiting the subjects, and clarity of the questionnaire. Also to check for understanding, time required for filling the questionnaire, and to test the psychometric prosperities of the questionnaire. The psychometric properties of the CCFNI were tested on a large sample size [15]. The questionnaire was tested for face and content validity by an expert panel. A Cronbach alpha reliability of 0.92 was demonstrated. A principal components factor analysis with verimax and oblimin rotations revealed five factors: support (14 items), comfort (6 items), information (9 items), proximity (9 items), assurance (7 items) [15]. It was translated to Arabic language by competent person then a reverse translation to English language made by another competent person. No variation was identified between the two translations. The instrument has two modules; the first module consists of 45 needs items, the second module consist of questionnaire related to sociodemographic data.

\section{Results}

\subsection{Sample Characteristics}

The study sample consisted of 60 family members, $55 \%$ of the sample was male and young adult in a range of 20 - 55 years $(\mathrm{M}=35$ years), 25 family members $(41.7 \%)$ had completed the primary and secondary level of education and 31 (51.7\%) had baccalaureate degree, only 4 family members (6.7\%) had higher education. About $51.7 \%$ of the family members were sons and daughters, $16.7 \%$ were wife and husband, $15 \%$ were brothers and sisters, $10 \%$ were parents, and the remains were other relatives. Almost $70 \%$ of the participants had no previous admission to their patient to critical care unit. Only $23.3 \%$ of participants worked in past or currently with health 
team. The hospitalized, critically ill patients were mostly male (61.7\%) and older adults ( $\mathrm{M}=51.86$ years).

\subsection{Family Needs}

The 16 top important and very important needs for family members were in Table 1.

However, only five needs were perceived as important and very important by more than $96 \%$ of the sample. Their needs were "To feel there is hope", "To have questions answered honestly", "To know the expected outcome", "To be assured the best possible care is being given", "To feel that hospital personnel care about patient", all of these items were related to assurance. So, seven of 16 top important and very important needs were related to assurance, two related to comfort, two related to proximity, four related to information and one related to support.

Mean scores of the five domains of needs using Leske's (1991) categorization were also calculated, the sample was ranked needs for assurance the highest $(\mathrm{M}=92.38$, $\mathrm{SD}=7.79)$ then followed by information and proximity in second important needs $(M=80.78, S D=10.30),(M=80.32, S D=10.90)$ respectively.

Third ranked important needs were support $(M=72.91, S D=10.95)$ and comfort $(M=75.62, S D=11.85)$.

The 5 needs which ranked as least and not important for family members were in Table 2.

\subsection{Met and Unmet Needs}

The top needs that were met and unmet are shown in Table 3 and Table 4, respectively.

Table 1. The top important and very important needs for family members.

\begin{tabular}{clc}
\hline Number & \multicolumn{1}{c}{ Need statements } & Percentage of the sample \\
\hline 1 & To feel there is hope & 98.3 \\
2 & To have questions answered honestly & 98.3 \\
3 & To know the expected outcome & 96.7 \\
4 & To be assured the best possible care is being given & 96.7 \\
5 & To feel that hospital personnel care about patient & 96.7 \\
6 & To be assured it is all right to leave the hospital for a while & 95 \\
7 & To know specific facts concerning patient's progress & 95 \\
8 & To talk to the doctor every day & 95 \\
9 & To feel accepted by the hospital staff & 95 \\
10 & To have explanations given that are understandable & 95 \\
11 & To know which staff members could give what information & 95 \\
12 & To see the patient frequently & 95 \\
13 & To have directions as to what to do at the bedside & 93.4 \\
15 & To help with the patient's physical care & 93.3 \\
16 & To be told about transfer plans while they are being made & 92.6 \\
\hline
\end{tabular}

Table 2. The needs were least important and not important for family members.

\begin{tabular}{clc}
\hline Number & Need statements & Percentage of the sample \\
1 & To have good food available while in the hospital & 60 \\
2 & To have a pastor visit & 60 \\
3 & To have another person with you when visiting critical care unit & 58.3 \\
4 & To have a place to be alone while in the hospital & 53.3 \\
5 & To be told about chaplain services & 53.3 \\
\hline
\end{tabular}


Table 3. The top needs that were met.

\begin{tabular}{|c|c|c|c|}
\hline Number & Need statements & Met percentage & Important percentage \\
\hline 1 & T o have friends nearby for support & 75 & 86.6 \\
\hline 2 & To feel there is hope & 56.7 & 98.3 \\
\hline 3 & To know the expected outcome & 56.7 & 96.7 \\
\hline 4 & To be assured it is all right to leave the hospital for a while & 56.7 & 95 \\
\hline 5 & To know specific facts concerning patient's progress & 51.7 & 95 \\
\hline 6 & To have questions answered honestly & 51.7 & 98.3 \\
\hline 7 & To be assured the best possible care is being given & 55 & 96.7 \\
\hline 8 & To feel that hospital personnel care about patient & 50 & 96.7 \\
\hline 9 & To be told about transfer plans while they are being made & 50 & 92.6 \\
\hline
\end{tabular}

Table 4. The top needs that were unmet.

\begin{tabular}{|c|c|c|c|}
\hline Number & Need statements & Not met percentage & Important percentage \\
\hline 1 & To have comfortable furniture in the waiting room & 96.7 & 76.6 \\
\hline 2 & To have a pastor visit & 93.3 & 40 \\
\hline 3 & To have the waiting room near the patient & 91.7 & 76.6 \\
\hline 4 & To have a telephone near the waiting room & 90 & 56.7 \\
\hline 5 & To be told about chaplain services & 90 & 46.7 \\
\hline 6 & To have a bathroom near the waiting room & 85 & 68.4 \\
\hline 7 & To have good food available while in the hospital & 81.7 & 40 \\
\hline 8 & To be told about someone to help with family problems & 80 & 65 \\
\hline 9 & To be told about people who could help with problems & 75 & 86.7 \\
\hline 10 & To be called at home about changes in the condition & 73.3 & 75 \\
\hline 11 & To have visiting hours changed for special conditions & 53.3 & 83.3 \\
\hline
\end{tabular}

The highest unmet was support $(\mathrm{M}=31.50, \mathrm{SD}=4.36)$ and the lowest unmet was assurance $(\mathrm{M}=10.93$, SD $=2.63)$.

Nurses and doctors were found to be the primary and most important people available to meet the family members need. However, families in this study viewed nurse as the most important source to meet their needs (63.3\%).

\subsection{Characteristics of Family}

A significant correlation between relationship to patient and need importance was found in this study, parents and wife/husband rated some needs as significantly more important than did other relatives, assurance correlate with relationship ( $\mathrm{r}=-0.317, P=0.014)$ and information $(\mathrm{r}=-0.310, P=0.016)$. Assurance and information needs figured highly $(\mathrm{M}=92.38, \mathrm{M}=80.78$ ) respectively. Members with a higher educational and socioeconomically status were ranked assurance and information as more important than those with a lower educational and socioeconomically status.

There was significant relationship between unmet need score and relationship of family member to patient (F $=2.68, P=0.041)$, sister and brother were rating the highest unmet need score in support, in contrast of mother and father were rating the lowest unmet need score in assurance ( $\mathrm{F}=7.08, P=0.001)$. Otherwise, there were no statistically significant correlations between needs importance or unmet needs score and other demographic variables.

\section{Discussion}

The majority of Jordanian families perceive 16 needs out of 45 as important and very important; these needs were related to assurance, comfort, information, proximity and support. The top five needs were related to as- 
surance only and these needs were met for $50 \%-56.7 \%$ and this is not congruent with Omari study [16]. The Jordanian families expressed their traditional beliefs of obligations, roles and the interdependent relationship of the family. This traditional family relationship was evident in the significant correlation between relationships with subscale of needs as clear in Table 3. This result is contradicted by other researcher who found that support and proximity were the most important needs [17].

In Jordanian family, the daughters and wife are usually expected to be the one who takes care of household affairs and general health of every family member. This finding might indicate that the major concern of Jordanian families is the health condition of their critically ill relatives [7].

Parents and wife/husband rated that some needs are significantly more important than other relatives did. Nurses should consider the degree of relationship when meeting the needs of family members.

Assurance and information need to be figured highly $(M=92.38, M=80.78)$ respectively. Families were eager to identify the patient's progress and lack of current information about the patient served to elevate the level of their anxiety. This result is contradicted by other study [18]. Assurance is a strategy that aids in alleviating stress and reducing uncertainty. This finding is congruent with the results of other studies [16] [19] [20]. The item "To feel there is hope" had ranked as the highest important need for the family so promotion of realistic hope in family members of critically ill patients can be an important intervention to provide assurance. While in Omari (2009) study, the item "To be assured that the best care possible is being given to the patient" was ranked as the most important need which is the fourth important in the current study [16].

Families of critically ill patients might need information to be certain about the progress of the patient' condition and they sometimes ask the same question repeatedly, talk incessantly or request more information about the patient. In response to these emotions, nurse should strive to understand the experience from the family's point of view and to be aware that provision of adequate information about the patient, treatment and procedures, unit policies and personnel can relieve the family's anxiety. Nurses, therefore, should give realistic information to families and let them ventilate their feelings about the patient's condition.

Needs for proximity or remaining near the critically ill patients ranked in third level, "To see the patient frequently" was very important, and also "To be told about transfer plans while they are being made" came in the second need in proximity. Observing the patient's body provides direct information about the progress of the patient's health condition. Restrictive visiting policies may interfere with the family need to care for their physically ill patients; families are always longing to be informed and to have a chance to participant in physical care during visiting times.

Needs for support and comfort were ranked the lowest. This suggested that families of critically ill patients gave less value to support and comfort needs although they were needs throughout life. Under comfort subscale the item "To have good food available while in the hospital" was not important in $60 \%$ of the sample, although food is basic need of human and physiological need of life. Under support sub-scale the items "To have another person with you when visiting critical care unit" and "To have place to be a lone while in the hospital" were not important in above half of sample 53.3\%.

The inventory operationalized comfort as a unidimensional need. This inventory focuses on physical environmental needs of comfort only. Comfort is a multidimensional construct that has been defined as the state of having met basic human needs for relief, ease and transcendence in four contexts of experience including physical, environmental, psycho-spiritual and social culture [7].

The following needs for support and comfort were ranked the lowest needs and the families considered them less important because mostly they are personal needs: waiting rooms, place that can family members stay at alone, comfortable furniture and good food. (81.7\%) of the sample stated that these needs did not met and this is explained by no open visitation policies. In this study, most of unmet needs were identified related to hospital facilities (e.g. furniture, waiting room, telephone and bathroom) and unit policy (e.g. visiting hours). Similarly, the literature has suggested that a waiting area with comfortable furniture should be provided near the patient because a supportive environment is important for the well-being of family members [4]. Close proximity with the patient was one way that family members coped with a critical illness event [3]. Although administrators and nurses traditionally believed that visiting not only disrupted the delivery of care but also put extra pressure on patients, and also rather than doing harm to patient, visiting can in fact help to calm patients and reduce their anxiety [21]. In any intervention program, nurses must recognize the family needs to receive accurate and understandable information [7].

Relationship among the selected demographic data using correlation test were positive significant relationship 
between level of education and who met the needs of family members ( $r=0.322, P=0.012$ ); family member who has higher education showed that the nurses are the best to meet their needs.

Female subjects rated the needs to comfort sub scale as more important than male subjects $(\mathrm{t}=-0.374, P=$ 0.007). Two factors might have contributed to this finding. First, men were usually the breadwinners of the family and so were usually unable to visit frequently. In contrast, women might have more time to visit. Second, comfort need might be more important in women [4]. However, the importance of these two factors should be validated by further studies.

Apparently, the need for assurance and information is universal and extremely important for all family members $(\mathrm{F}=2.62, P=0.044)$; $(\mathrm{F}=4.41, P=0.004)$ respectively.

There was significant relationship between unmet need score and relationship of family member to patient, sister and brother were rating the highest unmet need score in support, in contrast of mother and father were rating the lowest unmet need score in assurance. Otherwise, there were no statistically significant correlations between needs importance or unmet needs score and other demographic variables.

\section{Conclusions}

\subsection{Implications for Nursing Practice}

All studies show that family members give priority to the welfare of their relative. In their confused state, they often do not get around to paying attention to themselves. Personal needs are set aside, even when the patient remains in ICU for a longer period of time. The need for accurate and comprehensive information that leaves room for hope is universal. Family member with less education required extra attention.

A holistic approach of nursing management requires that nurses assess family needs using valid and reliable tools and develop intervention strategies to meet the identified individualized needs. Specifically, family's need for information about their patient's condition and honest and respectful care are critical needs that require special attention from nurses and other healthcare professionals. Nursing assessment and education should also focus on the key psychosocial needs that have been repeatedly identified as important to family members and family members' relationship with the patient.

\subsection{Recommendation for Further Research}

Further studies with a larger sample size and recruit subjects from different ICU settings are recommended to validate the findings. Long-term effects of a critical illness on the family should be studied to help care planning for families facing the recovery or death of the patient.

Finally, the findings about the needs of Jordanian families can be considered as a baseline for planning and evaluating a specific nursing intervention to meet needs or reduce unmet needs.

\section{References}

[1] Price, D., Forrester, D., Murphy, P. and Monghan, J. (1991) Critical Care Family Needs in an Urban Teaching Medical Center. Heart and Lung, 20, 183-188.

[2] Molter, N. (1979) Needs of Relatives of Critically Ill Patients: A Descriptive Study. Heart and Lung, 8, 332-339.

[3] Leske, J. (1986) Needs of Relatives of Critically Ill Patient: A Follow-Up. Heart and Lung, 15, 189-193.

[4] Lee, L. and Lau, Y. (2003) Immediate Needs of Adult Family Members of Adult Intensive Care Patients in Hong Kong. Journal of Clinical Nursing, 12, 490-500. http://dx.doi.org/10.1046/j.1365-2702.2003.00743.x

[5] Eldelman, C. and Mandle, C. (1990) Health Promotion throughout the Life Span. 2nd Edition, CV Mosby, Missouri.

[6] Azoulay, E., Pochard, F., Chevert, S., Lemare, F., Mokhtari, M., Gall, J., et al. (2001) Meeting the Needs of Intensive Care Unit Patient Families: A Multicenter Study. American Journal of Respiratory and Critical Care Medicine, 163, 135-139. http://dx.doi.org/10.1164/ajrccm.163.1.2005117

[7] Al-Hassan, M. and Hweidi, I. (2004) The Perceived Needs of Jordanian Families of Hospitalized, Critically Ill Patients. International Journal of Nursing Practice, 10, 64-71. http://dx.doi.org/10.1111/j.1440-172X.2003.00460.x

[8] Lee, I., Chien, W. and Machenzie, A. (2002) Needs of Families with a Relative in Critical Care Unit in Hong Kong. Journal of Clinical Nursing, 9, 46-54. http://dx.doi.org/10.1046/j.1365-2702.2000.00315.X

[9] Holden, J., Harrison, L. and Johanson, M. (2002) Families, Nurses and Intensive Care Patients: A Review of the Literature. Journal of Clinical Nursing, 11, 140-148. http://dx.doi.org/10.1046/j.1365-2702.2002.00581.x 
[10] Jamerson, P., Scheibmeir, M., Bott, M., Crighton, F., Ruthellyn, H. and Cobb, A. (1996) The Experiences of Families with a Relative in Intensive Care Unit. Heart and Lung, 25, 467-474. http://dx.doi.org/10.1016/S0147-9563(96)80049-5

[11] Wong, F. (1995) The Needs of Families of Critically Ill Patients in a Chinese Community. Hong Kong Nursing Journal, 69, 25-29.

[12] Bijttebier, P., Delva, D., Vanoost, S., Bobbaers, H., Lauwers, P. and Vertommen, H. (2000) Reliability and Validity of the Critical Care Family Needs Inventory in a Dutch-Speaking Belgian Sample. Heart and Lung, 29, 278-286. http://dx.doi.org/10.1067/mhl.2000.107918

[13] Auterbach, S., Kiesler, D., Wartella, J., Rausch, S., Ward, K. and Ivatury, R. (2005) Optimism, Satisfaction with Needs Met, Interpersonal Perceptions of the Health Care Team, and Emotional Distress in Patient's Family Members during Critical Care Hospitalization. American Journal of Critical Care, 14, 202-210.

[14] Polit, D. and Beck, C. (2004) Nursing Research: Principles and Methods. 7th Edition, Lippincott Company, Philadelphia.

[15] Leske, J. (1991) Internal Psychometric Properties of the Critical Care Family Needs Inventory. Heart and Lung, 20, 236-244.

[16] Omari, F.H. (2009) Perceived and Unmet Needs of Adult Jordanian Family Members of Patients in ICUs. Journal of Nursing Scholarship, 41, 28-34. http://dx.doi.org/10.1111/j.1547-5069.2009.01248.X

[17] Noor Siah, A.A., Ho, S.E., Jafaar, M.Z., Choy, Y.C., Das, S., Ismail, S.M. and Barnett, A. (2012) Information Needs of Family Members of Critically Ill Patients in Intensive Care Unit of a Tertiary Hospital. La Clinica Terpeutica, 163, 63-67.

[18] Bailey, J.J., Sabbagh, M., Loiselle, C.G., Boileau, J. and McVey, L. (2010) Supporting Families in the ICU: A Descriptive Correlational Study of Informational Support, Anxiety, and Satisfaction with Care. Intensive and Critical Care Nursing, 26, 114-122. http://dx.doi.org/10.1016/j.iccn.2009.12.006

[19] Hweidi, I.M. and Al-Shannag, M.F. (2014) The Needs of Families in Critical Care Settings—Are Existing Findings Replicated in a Muslim Population: A Survey of Nurses’ Perception. European Journal of Scientific Research, 116, 518-528.

[20] Chatzaki, M., Klimathianaki, M., Anastasaki, M., Chatzakis, G., Apostolakou, E. and Georgopoulos, D. (2012) Defining the Needs of ICU Patient Families in Suburban/Rural Greek Population: A Prospective Cohort Study. Journal of Clinical Nursing, 21, 1651-1658. http://dx.doi.org/10.1111/j.1365-2702.2011.04022.x

[21] Simpson, T. (1991) Critical Care Patient’s Perception of Visit. Heart and Lung, 20, 681-688. 
Scientific Research Publishing (SCIRP) is one of the largest Open Access journal publishers. It is currently publishing more than 200 open access, online, peer-reviewed journals covering a wide range of academic disciplines. SCIRP serves the worldwide academic communities and contributes to the progress and application of science with its publication.

Other selected journals from SCIRP are listed as below. Submit your manuscript to us via either submit@scirp.org or Online Submission Portal.
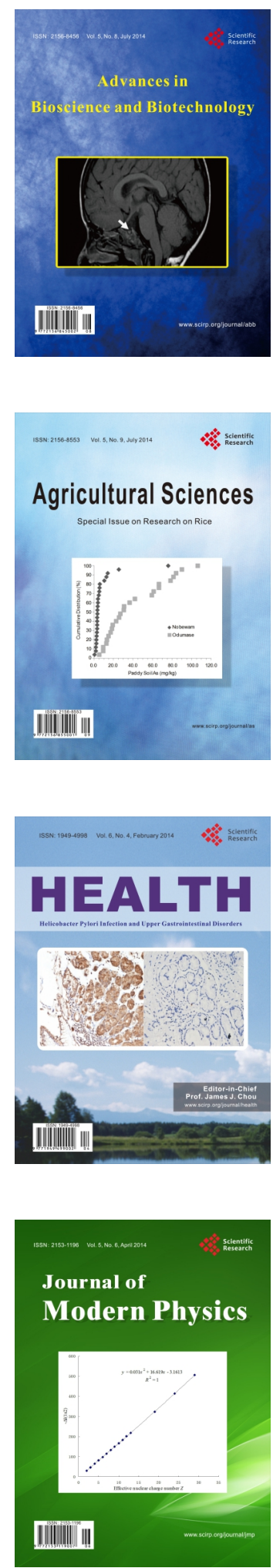
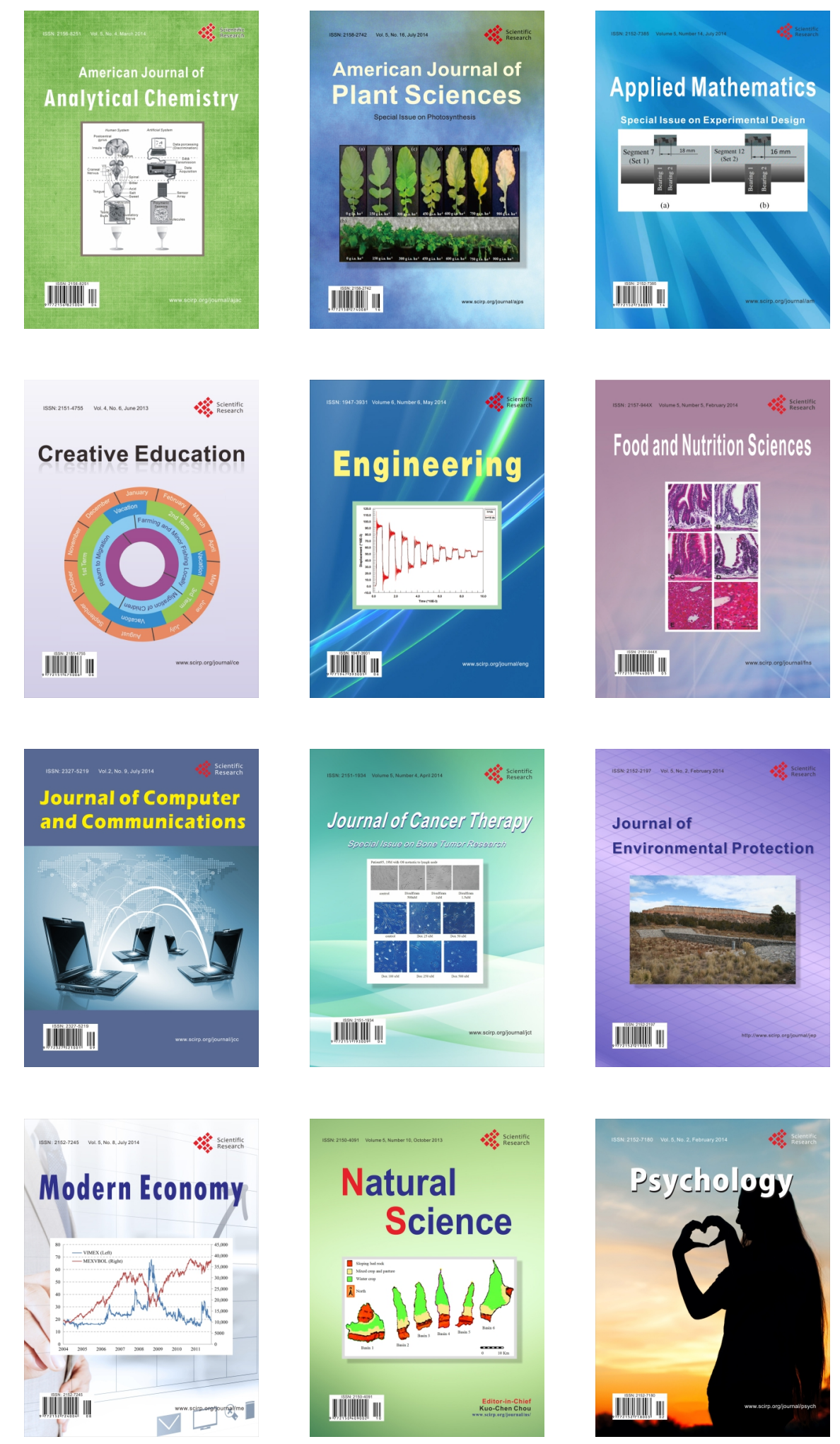